\title{
Relationship Between Long-Term Beetroot Juice Supplementation and Hematological Parameters in Elite Fencers - a Pilot Study
}

\author{
Olga Mizera ${ }^{1}$, Lucyna Kozlowska ${ }^{1}$, Ewelina Hallmann ${ }^{2}$, Jolanta Gromadzinska ${ }^{3}$, \\ Anna Mroz ${ }^{4} \&$ Wojciech Wasowicz ${ }^{3}$ \\ ${ }^{1}$ Department of Dietetics, Warsaw University of Life Sciences, Warsaw, Poland \\ ${ }^{2}$ Department of Functional and Organic Food, Warsaw University of Life Sciences, Warsaw, Poland \\ ${ }^{3}$ Department of Biological and Environmental Monitoring, Nofer Institute of Occupational Medicine, Lodz, \\ Poland \\ ${ }^{4}$ Department of Physiology and Sport Medicine, Jozef Pilsudski University of Physical Education in Warsaw, \\ Warsaw, Poland \\ Correspondence: Olga Mizera, Department of Dietetics, Warsaw University of Life Sciences, Warsaw, Poland. \\ E-mail: olga_mizera@sggw.pl
}

Received: August 24, 2020 Accepted: October 27, 2020 Online Published: November 10, 2020

doi:10.5539/gjhs.v12n13p73 URL: https://doi.org/10.5539/gjhs.v12n13p73

\begin{abstract}
Objective: This study aimed to analyze the long-term (4 weeks) effect of a diet and beetroot juice supplementation on hematological parameters, glutathione peroxidase activity in erythrocytes (GPx), and physical performance in elite fencers.

Methods: The study included 20 fencers and was conducted during the preparatory phase. Fencers underwent the fitness $\mathrm{VO}_{2 \max }$ test at baseline - (B) and after two stages of implementation of the dietary recommendations - the first 4 weeks without beetroot juice (D) and the second with $26 \mathrm{~g} / \mathrm{d}$ of freeze dried beetroot juice supplementation (D\&J). At B and after D and D\&J fasting blood samples were collected.
\end{abstract}

Results: After D and D\&J activities of GPx were significantly higher than those in $\mathrm{B}(p<0.000, p=0.005-$ respectively). After D\&J versus D significant increased red blood cells count $(p=0.038)$ and hemoglobin $(p=$ $0.029)$, as well as decreased platelet count $(p=0.007)$, were observed. Additionally, after D\&J versus B a higher level of mean platelet volume ( $p=0.043)$, energy $(p=0.001)$, and carbohydrate intake $(p<0.000)$ were observed and a lower level of red cell distribution width $(p=0.006)$.

Conclusion: Our findings provide evidence that long-time consumption of beetroot juice may improve some hematological parameters (red blood cells count, hemoglobin, platelet count, mean platelet volume) - one of the key elements of physical performance. However, seems to be that this effect is largely determined by an appropriate level of energy and nutrients intake.

Keywords: athletes, beetroot juice, blood morphology, glutathione peroxidase activity in erythrocytes, nutrients

\section{Introduction}

Red beetroot - Beta vulgaris var. rubra is known as a rich source of inorganic nitrate $\left(\mathrm{NO}_{3-}\right)$. The capacity of this inorganic anion has received considerable attention in recent years and very quickly has become a very popular dietary supplement that improves health and performance (Lundberg, Weitzberg, \& Gladwin, 2008). Beetroot is also a source of carbohydrates, fiber, proteins, and minerals (sodium, potassium, calcium, and iron), and it is additionally a rich source of many other bioactive compounds, including phenolic acids, flavonoids, and phenolic amides with betalains. Screening of phenolic compounds demonstrated the presence of 4-hydroxybenzoic acid, caffeic acid, and chlorogenic acid in concentrations ranging from 0.12 to $0.047 \mathrm{mg} / \mathrm{g}$ of dry extract (Georgiev et al., 2010). This vegetable also constitutes a good source of such flavonoids as catechin-hydrate, epicatechin, rutin as well as betagarin, betavulgarin, cochliofilin, and dihydroxyisorhamnetin (Georgiev et al., 2010; Kujala, Vienola, Klika, Loponen, \& Pihlaja, 2002). Beetroot contains a large number of betalains: yellow-orange betaxanthins (major component - vulgaxanthin I) and the red-violet betacyanins (major pigment is betanin that is a betanidin-5-O $\beta$-glucoside), the concentrations of which are in the ranges from $0.04-0.21 \%$ and $0.02-0.14 \%$, 
respectively (Kugler, Graneis, Stintzing, \& Carle, 2007). In beetroot, two additional phenolic amides were also identified, i.e. N-transferuloyltyramine and N-trans-feruloylhomovanillylamine (Kujala et al., 2002).

Multiple studies support the thesis that $\mathrm{NO}_{3-}$ supplementation (also in a form of beetroot juice) has demonstrated modest benefits pertaining also to cardiovascular health such as reduced blood pressure and improvements in other markers of vascular health (platelet aggregation, arterial stiffness, endothelial function, ischemia-reperfusion injury, blood flow), (Bondonno et al., 2018). Concering the physical performance effects of $\mathrm{NO}_{3-}$ supplementation (mainly via beetroot juice), many authors have reported improvement in finish times (Bond, Morton, \& Braakhuis, 2012), reduction of the total $\mathrm{O}_{2}$ cost of exercise, elongation of time till exhaustion (Bailey et al., 2009), raise of work rate (Lansley et al., 2011) and a peak of power (Kelly, Vanhatalo, Wilkersson, Wylie, \& Jones, 2013). The benefits of beetroot juice supplementation mentioned above noted following a single bolus or a relatively short period are very promising. However, additional research is needed to determine the impact of beetroot juice supplementation in the long-term period. This represents a significant gap in the literature.

Bearing in mind that beetroot is a very good source of bioactive antioxidant compounds, as well as that hematological parameters such as elevated red blood cell (RBC), hemoglobin (HGB) and hematocrit (HCT) are generally associated with better blood oxygen transport, aerobic performance and blood viscosity (Hu et al., 2008), thecurrent investigation aimed to analyze the long-term (4 weeks) effect of a diet and beetroot juice supplementation on hematological parameters and physical performance in elite fencers.

\section{Method}

\subsection{Participants}

At baseline 24 experienced fencers (national team) were recruited however, 4 people did not complete the study due to various reasons (minor injuries in 2 players, health problems in 1 player and personal problems in 1 player). Finally, 10 women age and 10 men completed the study. During the entire study period which was conducted during the preparatory phase from September to December, the athletes were asked not to take dietary supplements and other ergogenic agents. Exclusion criteria were as follows: the use of alternative diets, smoking, the occurrence of chronic diseases, taking antibiotics and steroid or non-steroidal anti-inflammatory drugs, and in the case of women irregular menstruation. The study was approved by the Ethics Committee of the Nofer Institute of Occupational Medicine (NR 05/2015). All the subjects gave their written informed consent to participate in the study.

\subsection{Experimental Design}

The research program consisted of a baseline analysis (B), a stage with the implementation of dietary recommendations without beetroot juice supplementation (D) and after that, a stage with the implementation of dietary recommendations and beetroot juice supplementation (D\&J). The duration of each stage was 4 weeks. After each stage, the fencers visited a laboratory after fasting all night and were instructed to empty their bladder and collect a urine sample. Then, the body composition was measured and a venous blood sample was taken. After that a meal with a particular composition was consumed (Kozlowska, Mizera, \& Mroz, 2020). After B and D the fencers before the maximum rate of oxygen uptake test $\left(\mathrm{VO}_{2 \max }\right)$ consumed a meal with maltodextrin but after D\&J - with freeze-dried beetroot juice. The meal was consumed within 15 minutes and two hours later a $\mathrm{VO}_{2 \max }$ test was performed. The research plan is shown in Figure 1. 


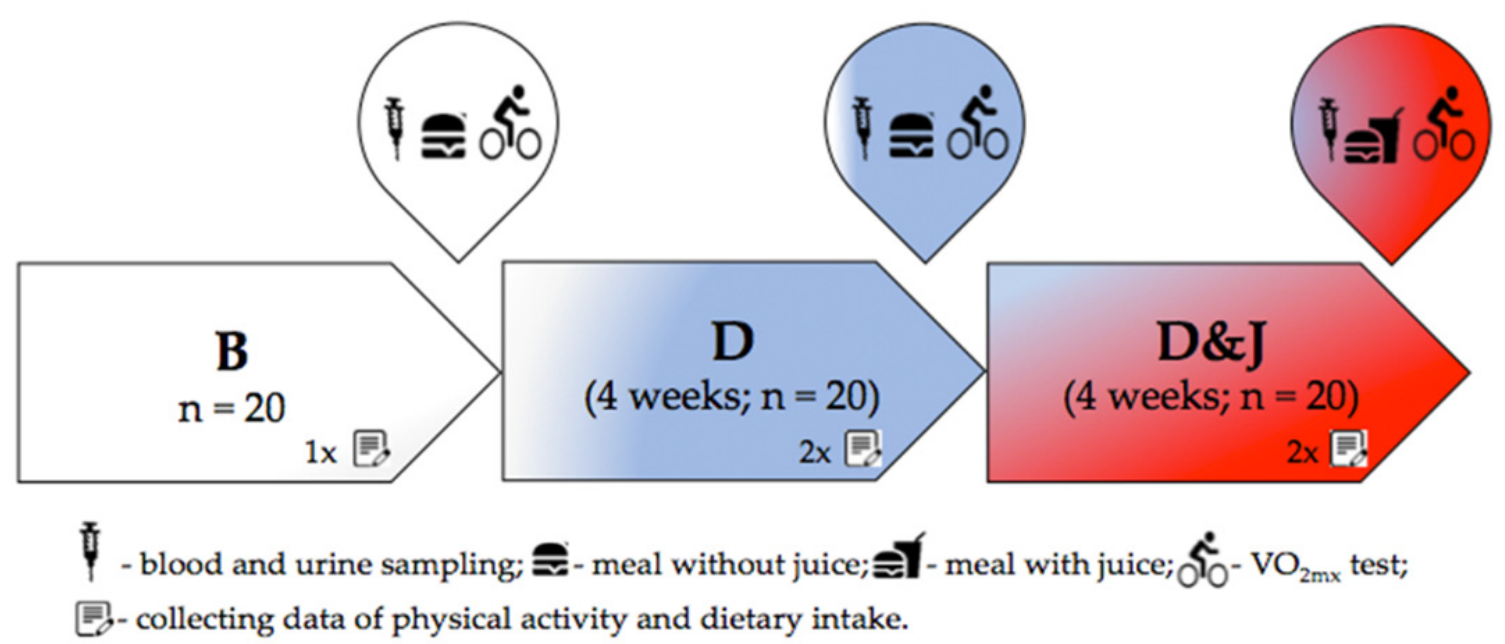

Figure 1. Study design. On the last day of each stage, blood samples were collected and after a special meal, a maximum rate of oxygen uptake (VO2max) test was conducted. $\mathrm{B}$, the first stage of the study (baseline characteristic); D, the second stage of the study (implementation of dietary recommendations without beetroot juice supplementation); D\&J, the third stage of the study (implementation of dietary recommendations with beetroot juice supplementation)

\subsection{Anthropometry and Body Composition}

The weight of the fencers and body composition was measured using bioimpedance analyzer BC418MA (Tanita, Tokyo, Japan) with a constant current frequency of $50 \mathrm{kHz}$ and a system. The measurements were performed following the standard requirements (Kyle et al., 2004).

\subsection{Dietary Recommendations, Nutrition, and Physical Activity Monitoring}

At baseline and two times at each stage (in the 2nd, 4th, 6th, and 8th week of the study) the fencers filled-in the 3-day physical activity logbook and the 3-day dietary records of consumed food and beverages. The filled in information came from the following three days: the day with a fencing training, the day with a general training, and a day free from training. Based on the information collected from a 3-day physical activity logbook and energy cost of physical activities (Ainsworth et al., 2011) the mean physical activity level was assessed on the days with a fencing training (PA-FT), on the days with a general training (PA-GT) and on free from training days (PA-FD). Because there were no significant differences in the level of physical activity and nutrient intake in the second and fourth weeks as well as in the sixth and eighth weeks, the data were averaged.

Total energy demand for each person was estimated at a baseline stage based on the filledin physical activity logbook and energy cost of physical activities (Metabolic Equivalent of Task - MET), (Ainsworth et al., 2011). Energy availability (EA) was also calculated as energy intake (kcal) minus exercise energy expenditure (kcal) divided by fat free mass $(\mathrm{kg})$, (Mountjoy et al., 2018). The athletes received dietary recommendations with individually calculated energy and nutrients values, together with a plan of meals. Nutritional recommendations for the athletes regarding protein intake (Potgieter, 2013) were incorporated into developing personalized diet plans. Dietary recommendations for the intake of other nutrients were at the level for the general population (Jarosz et al., 2017). A card of dietary recommendations was based on nutritional replacements with photos of basic portions of each group of products at a 1:1 scale. The recommendations included such days: a fencing training day, a general training day, and a day free from training. Estimation of individual energy demand for each fencer on each kind of day was estimated by multiplying resting energy expenditure and an individually calculated physical activity level (Jarosz et al., 2017). To obtain the right amount of energy and macronutrients in diets the right amount of replacements was selected. To obtain the right amount of vitamins and minerals in diets, the rules of menu layout were used. During the beetroot juice supplementation period, freeze-dried beetroot juice ( $26 \mathrm{~g}$ ) after dissolving in water was consumed once a day. In the assessment of diet in the stage D\&J the energy value of beetroot juice was taken into account. A computer program Dieta 5 (Warsaw, Poland) was used to determine daily energy and nutrients intake. 


\subsection{Aerobic Performance Test - Maximum Rate of Oxygen Uptake $\left(\mathrm{VO}_{2 \max }\right)$}

Aerobic capacity was assessed based on the $\mathrm{VO}_{2 \max }$ index measured using the direct method during the progressive test performed on the Ergoselect 200 Ergoline GmbH bicycle ergometer (Bitz, Germany). The Mes 2000 ergospirometer (Cracow, Poland) was used to measure the respiratory system indices. Every day before starting the tests, gas, and ventilation calibration of the ergosprometer was performed. For 1 minute before the start of physical exercise, the indicators were measured at rest, and then the exercise test with a gradually increasing load was started. The first load was $50 \mathrm{~W}$ and lasted 5 minutes as part of a warm-up. Then the load increased every 3 minutes by $50 \mathrm{~W}$, at the recommended rotation number of 60 per minute. The athletes continued their effort till refusal, i.e. until they were unable to continue their physical effort.

\subsection{Preparation and Chemical Analyses of the Beetroot Juice}

The detailed procedure involved in the preparation of freeze-dried beetroot juice has been described earlier (Kozlowska et al., 2020). In the beetroot juice samples concentrations of polyphenols (flavonoids and phenolic acids), total and reduced sugars, betacyanins, vitamin $\mathrm{C}$, and organic acids were analyzed. All the analyses were carried out using validated protocols and methods. Polyphenols were measured by the use of the HPLC method (Hallmann et al., 2017). The sample preparation included extraction of the samples $(100 \mathrm{mg})$ with methanol $80 \%$ $(5 \mathrm{~mL})$ in plastic tubes with an ultrasonic bath $\left(10 \mathrm{~min}, 30^{\circ} \mathrm{C}\right)$. The wavelength used for detection was $270-360$ $\mathrm{nm}$. External standards of polyphenols from Sigma-Aldrich and Fluka (Warsaw, Poland) all with the purity of $95.00-99,9 \%$ were used. The content of polyphenols was calculated based on standard curves and samples dilution coefficient.

Sugars (glucose, fructose, and sucrose) were measured usingthe HPLC method. The sample preparation included extraction of the samples $(100 \mathrm{mg})$ with $80 \%$ acetone $(5 \mathrm{~mL})$ in plastic tubes with an ultrasonic bath $(10 \mathrm{~min}$, $\left.10{ }^{\circ} \mathrm{C}\right)$. In the next step the samples were centrifuged $\left(10 \mathrm{~min}, 6000 \mathrm{rpm}, 0{ }^{\circ} \mathrm{C}\right)$. Into HPLC-vial, $1 \mathrm{~mL}$ of supernatant was transferred. To determine sugars we used the HPLC set-up consisting of two LC-20AD pumps, a CMB-20A system controller, a SIL-20AC autosampler, a refractive RID-10A detector, a CTD-20AC oven, and a Luna-RP 80A column $(250 \times 4.60 \mathrm{~mm})$ all from Shimazu (Kyoto, Japan). An isocratic mobile phase $(80 \%$ of acetone) at a flow rate of $1.5 \mathrm{~mL} / \mathrm{min}$ was used. External standards of sugars from Sigma-Aldrich and Fluka (Warsaw, Poland) with $99.9 \%$ purity were used. The content of sugars was calculated based on standard curves and samples dilution coefficient.

Betacyanins were measured using the HPLC method (Shepherd et al., 2015). The sample preparation included extraction of the samples $(100 \mathrm{mg})$ with Bolo methanol $(5 \mathrm{~mL})$ in plastic tubes with an ultrasonic bath (10 min, $10{ }^{\circ} \mathrm{C}$ ). The wavelength used for detection was 530-570 $\mathrm{nm}$. External standards of betanidine and glucoside-3-0-betanin from Sigma-Aldrich and Fluka (Warsaw, Poland) all with a purity of 95.00-99,99\%, were used. The content of betacyanins was calculated based on standard curves and samples dilution coefficient.

Vitamin $\mathrm{C}$ content was determined by monitoring the oxidation of $\mathrm{L}$-ascorbic acid to dehydroxyascorbic acid in an acidic environment using 2, 6-dichorophenyloindophenol following The Estimation of Vitamin C in Fruit and Vegetables. Polish Norm PN-A-75101-11, 1990. The content of organic acids was measured by the HPLC method. The sample preparation included extraction of the samples $(100 \mathrm{mg})$ with hot deionized water in plastic tubes with an ultrasonic bath $\left(10 \mathrm{~min}, 80^{\circ} \mathrm{C}\right)$. In the next step, the samples were centrifuged $\left(10 \mathrm{~min}, 6000 \mathrm{rpm}, 2{ }^{\circ} \mathrm{C}\right)$. Into HPLC-vial, $1 \mathrm{~mL}$ of supernatant was transferred. To determine organic acids the HPLC set-up consisting of two LC-20AD pumps, a CMB-20A system controller, a SIL20AC autosampler, an ultraviolet-visible SPD-20AV detector, a CTD-20AC oven, and a Hydro-RP 80A column $(250 \times 4.60 \mathrm{~mm})$ all from Shimazu (Kyoto, Japan) was used. Phase A $20 \mathrm{mM}$ potassium 2-alkaline phosphate and phase B pure methanol at a flow rate of $1 \mathrm{~mL} / \mathrm{min}$ were used as gradient solvents. The wavelength used for detection was $250-280 \mathrm{~nm}$. External standards of acids (oxalic, citric, malic) from Sigma-Aldrich and Fluka (Warsaw, Poland) were used. The content of organic acids was calculated based on standard curves and samples dilution coefficient.

\subsection{Analysis of Blood Morphology and Glutathione Peroxidase Activity in Erythrocytes (GPX)}

Venous blood samples $(7.5 \mathrm{~mL})$ were collected into heparinized test tubes utilizing cubital venepuncture. Blood morphology was performed using standard methods in a diagnostic laboratory and was run on CELL-DYN Emerald Abbott (Illinois, U.S.A.) analyzer. The blood samples were centrifuged, plasma and buffy coat were removed, and erythrocytes were washed three times with an excess saline solution. Packed red blood cells were haemolysed by freezing and thawing.

The assay of GPx was measured at $25{ }^{\circ} \mathrm{C}$ according to the modified method of Paglia and Valentine (Paglia \& Valentine, 1967). The principle of measurement of the GPx activity was a nicotinamide adenine dinucleotide 
phosphate (NADPH) -coupled reaction whereby oxidized glutathione produced by GPx was reduced by exogenous glutathione reductase and NADPH. t-Butyl hydroperoxide was used as a substrate. The rate of reaction was measured spectrophotometrically as a change in absorbance at $340 \mathrm{~nm}$, at a temperature of $25^{\circ} \mathrm{C}$. The activity of the enzyme was defined as micromoles ( $\mu \mathrm{moL})$ of NADPH oxidized per min per gram hemoglobin $(\mathrm{u} / \mathrm{g} \mathrm{HGB})$. Intraassay variation $(\mathrm{CV})$ was $2.7 \%(\mathrm{n}=8)$. The samples were analyzed in single measurements. The measurement was repeated whenever the value was out of the range. The concentration of hemoglobin in lysates was assessed using the cyanmethemoglobin method with Drabkin's reagent and maximal absorbance of $540 \mathrm{~nm}$.

\subsection{Statistical Analysis}

Data normality was assessed by visual inspection of histograms and the Shapiro-Wilk test. Basic statistics for the data with normal distribution included mean and standard deviation (SD) and without normal distribution, median, and range. The normally distributed results obtained at consecutive stages were compared for statistical significance using a one-way ANOVA with repeated measures and the post-hoc Fisher test. Assumptions of ANOVA with repeated measures were as follow: lack of outliers (evaluated with the Grubb's test for all data points), normal distribution of the dependent variable (evaluated with the Shapiro-Wilk's test), the differences of variance between related groups are equal - sphericity (evaluated using the Mauchly's test). All of the conditions were met for our data and the analysis was performed as described. Differences between the paired data without normal distribution were analyzed with the nonparametric Wilcoxon signedrank test. Statistical significance was set at $p<0.05$. To examine correlations between the continuous variables, a correlation analysis (Pearson's correlation coefficient) was performed. All the statistical procedures were completed using Statistica (StatSoft Inc., Tulsa, OK, USA) version 13.1 software for Windows.

\section{Results}

The recruited elite fencers 10 female (age $22.6 \pm 4.7$ years, height $170.9 \pm 8.4 \mathrm{~cm}$ ) and 10 male (age $27.2 \pm 5.4$ years, height $185.9 \pm 5.3 \mathrm{~cm}$ ) fencers in $\mathrm{D} \& \mathrm{~J}$ drank beetroot juice dissolved in water in an amount of one glass per day and followed dietary recommendations. In D only dietary recommendations were implemented. All the analyzed variables before and after the consecutive stages from the study are summarized in Tables 1-2 and nutritional value of one portion of freeze-dried beetroot juice is presented in Table 3 .

In the study already after D significant changes in body composition: an increase of FFM $\%$ and a decrease of FM\% were observed and this effect lasted until the end of the study - D\&J.

Table 1. Anthropometric, physical activity, and biochemical parameters in fencers $(\mathrm{n}=20)$ participated in the study ${ }^{\mathrm{a}}$

\begin{tabular}{|c|c|c|c|c|c|c|}
\hline \multirow{2}{*}{ Variable } & \multicolumn{3}{|c|}{ Stages of the study } & \multirow{2}{*}{$\begin{array}{l}p \text { value }^{\mathrm{b}} \\
\text { (DC) }\end{array}$} & \multirow{2}{*}{$\begin{array}{l}p \text { value }^{\mathrm{c}} \\
\text { (DC) }\end{array}$} & \multirow{2}{*}{$\begin{array}{l}p \text { value }^{\mathrm{d}} \\
\text { (DC) }\end{array}$} \\
\hline & B & $\mathrm{D}$ & D\&J & & & \\
\hline \multicolumn{7}{|c|}{ Anthropometric and physical activity parameters } \\
\hline Weight (kg) & $74.5(51.7-93.9)$ & $75.0(51.2-94.4)$ & $75.7(51.5-94.2)$ & $0.794(-)$ & $0.644(-)$ & $0.575(-)$ \\
\hline FM (\%) & $22.08 \pm 6.28$ & $21.29 \pm 6.55$ & $20.78 \pm 6.07$ & $0.032(\downarrow)$ & $0.163(-)$ & $0.001(\downarrow)$ \\
\hline FFM (\%) & $77.93 \pm 6.28$ & $78.72 \pm 6.55$ & $79.23 \pm 6.07$ & $0.032(\uparrow)$ & $0.163(-)$ & $0.001(\uparrow)$ \\
\hline $\mathrm{VO}_{2 \max }(\mathrm{mL} / \mathrm{kg} / \mathrm{min})$ & $42.14 \pm 7.46$ & $42.36 \pm 7.85$ & $45.84 \pm 8.47$ & $0.683(-)$ & $0.001(\uparrow)$ & $0.000(\uparrow)$ \\
\hline PA - FT & $1.98 \pm 0.30$ & $1.92 \pm 0.22$ & $1.93 \pm 0.24$ & $0.211(-)$ & $0.830(-)$ & $0.299(-)$ \\
\hline PA - GT & $1.69 \pm 0.27$ & $1.77 \pm 0.21$ & $1.82 \pm 0.27$ & $0.148(-)$ & $0.340(-)$ & $0.018(\uparrow)$ \\
\hline PA - FD & $1.44 \pm 0.17$ & $1.42 \pm 0.14$ & $1.46 \pm 0.16$ & $0.677(-)$ & $0.488(-)$ & $0.781(-)$ \\
\hline \multicolumn{7}{|c|}{ Biochemical and hematological parameters } \\
\hline GPx (u/g HGB) & $20.71 \pm 4.54$ & $22.99 \pm 4.45$ & $25.01 \pm 3.78$ & $0.000(\uparrow)$ & $0.012(\uparrow)$ & $0.005(\uparrow)$ \\
\hline $\mathrm{WBC}\left(\times 10^{9} / \mathrm{L}\right)$ & $6.44 \pm 1.47$ & $5.76 \pm 1.19$ & $5.85 \pm 1.16$ & $0.020(\downarrow)$ & $0.756(-)$ & $0.042(\downarrow)$ \\
\hline $\operatorname{LYM}\left(\times 10^{9} / \mathrm{L}\right)$ & $2.23 \pm 0.58$ & $2.17 \pm 0.52$ & $2.17 \pm 0.54$ & $0.509(-)$ & $0.959(-)$ & $0.543(-)$ \\
\hline $\operatorname{MON}\left(\times 10^{9} / \mathrm{L}\right)$ & $0.37 \pm 0.08$ & $0.33 \pm 0.09$ & $0.35 \pm 0.07$ & $0.018(\downarrow)$ & $0.288(-)$ & $0.185(-)$ \\
\hline $\operatorname{GRA}\left(\times 10^{9} / \mathrm{L}\right)$ & $3.79 \pm 1.26$ & $3.25 \pm 1.08$ & $3.36 \pm 0.99$ & $0.052(-)$ & $0.072(-)$ & $0.115(-)$ \\
\hline $\operatorname{RBC}\left(\times 10^{12} / \mathrm{L}\right)$ & $4.70 \pm 0.37$ & $4.56 \pm 0.31$ & $4.70 \pm 0.46$ & $0.045(\downarrow)$ & $0.038(\uparrow)$ & $0.941(-)$ \\
\hline
\end{tabular}




\begin{tabular}{lllllll}
\hline HGB (g/dL) & $14.44 \pm 1.31$ & $14.16 \pm 1.34$ & $14.58 \pm 1.58$ & $0.139(-)$ & $0.029(\uparrow)$ & $0.465(-)$ \\
HCT (\%) & $42.47 \pm 3.50$ & $41.46 \pm 3.38$ & $42.49 \pm 4.73$ & $0.082(-)$ & $0.075(-)$ & $0.965(-)$ \\
MCV (fL) & $90.43 \pm 3.07$ & $90.39 \pm 3.68$ & $90.80 \pm 3.53$ & $0.945(-)$ & $0.427(-)$ & $0.467(-)$ \\
MCH (pg) & $30.74 \pm 1.20$ & $30.84 \pm 1.41$ & $31.19 \pm 1.63$ & $0.706(-)$ & $0.211(-)$ & $0.105(-)$ \\
MCHC (g/dL) & $34.00 \pm 0.65$ & $34.12 \pm 0.77$ & $34.34 \pm 0.93$ & $0.600(-)$ & $0.337(-)$ & $0.140(-)$ \\
RDW (\%) & $11.70 \pm 0.71$ & $11.46 \pm 0.68$ & $11.26 \pm 0.69$ & $0.134(-)$ & $0.201(-)$ & $0.006(\downarrow)$ \\
PLT (×10/L) & $228.3 \pm 48.7$ & $224.6 \pm 54.2$ & $204.0 \pm 42.1$ & $0.619(-)$ & $0.007(\downarrow)$ & $0.002(\downarrow)$ \\
MPV (fL) & $8.91 \pm 0.83$ & $9.10 \pm 0.77$ & $9.11 \pm 0.59$ & $0.060(-)$ & $0.881(-)$ & $0.043(\uparrow)$ \\
\hline
\end{tabular}

${ }^{\mathrm{a}}$ values are presented as mean \pm SD or as median and range; (DC), direction of change: (-) no significant changes, ( $\uparrow$ ) significant increase, $(\downarrow)$ significant decrease; $p$ value ${ }^{\mathrm{b}}, \mathrm{D}$ versus $\mathrm{B} ; p$ value ${ }^{\mathrm{c}}$, D\&J versus $\mathrm{D} ; p$ value ${ }^{\mathrm{d}}$, D\&J versus B (ANOVA with repeated measures and the post-hoc NIR Fisher test or Wilcoxon test). FM\%, fat mas percent; FFM $\%$, fat free mass percent; $\mathrm{VO}_{2 \max }$, maximum rate of oxygen uptake; PA-FT, mean physical activity level in days with fencing training; PA-GT, mean physical activity level in days with general training; PA-FD, mean physical activity level in free day; GPx, cytosolic glutathione peroxidase activity in erythrocytes; WBC, white blood cells; LYM, lymphocytes; MON, monocytes; GRA, granulocytes; RBC, red blood cells; HGB, hemoglobin; HCT, hematocrit; MCV, mean corpuscular volume; $\mathrm{MCH}$, mean corpuscular hemoglobin; $\mathrm{MCHC}$, mean corpuscular hemoglobin concentration; RDW, red cell distribution width, PLT, platelet count; MPV, mean platelets volume.

After D and D\&J activities of GPx were significantly higher than those in B. Such parameters as white blood cells (WBC), monocytes (MON), and RBC were significantly lower after D compared with B. Only after D\&J the fencers before the physical activity test consumed a meal with beetroot juice and only in this case a significant increase in $\mathrm{VO}_{2 \max }$ was observed. After this stage, in comparison with $\mathrm{D}$, such changes as increased RBC, HGB, carbohydrate intake, and decreased platelet count (PLT) were also observed. Additionally, after D\&J versus B a higher level of mean platelets volume (MPV), PA-GT, EA, energy, and carbohydrate intake was observed and a lower level of white blood cells (WBC), red cell distribution width (RDW), PLT, and intake of vitamin B $_{12}$ (Tables 1 and 2).

Table 2. Daily energy and selected nutrients intake in fencers $(n=20)$ participated in the study ${ }^{a}$

\begin{tabular}{|c|c|c|c|c|c|c|}
\hline \multirow{2}{*}{ Variable } & \multicolumn{3}{|c|}{ Stages of the study } & \multirow{2}{*}{$\begin{array}{l}p \text { value }^{\mathrm{b}} \\
\text { (DC) }\end{array}$} & \multirow{2}{*}{$\begin{array}{l}p \text { value }^{\mathrm{c}} \\
\text { (DC) }\end{array}$} & \multirow{2}{*}{$\begin{array}{l}p \text { value }^{\mathrm{d}} \\
\text { (DC) }\end{array}$} \\
\hline & $\mathrm{B}$ & $\mathrm{D}$ & D\&J & & & \\
\hline Energy (kcal/kg) & $30.9 \pm 7.4$ & $32.6 \pm 6.1$ & $34.5 \pm 6.3$ & $0.120(-)$ & $0.084(-)$ & $0.001(\uparrow)$ \\
\hline EA (kcal/kg FFM) & $23.03 \pm 8.93$ & $25.36 \pm 7.38$ & $28.10 \pm 7.31$ & $0.110(-)$ & $0.059(-)$ & $0.001(\uparrow)$ \\
\hline Protein $(\mathrm{g} / \mathrm{kg})$ & $1.46 \pm 0.42$ & $1.44 \pm 0.39$ & $1.35 \pm 0.35$ & $0.800(-)$ & $0.176(-)$ & $0.109(-)$ \\
\hline Fat $(\mathrm{g} / \mathrm{kg})$ & $1.23 \pm 0.40$ & $1.29 \pm 0.28$ & $1.30 \pm 0.33$ & $0.390(-)$ & $0.783(-)$ & $0.257(-)$ \\
\hline Carbohydrates (g/kg) & $3.79 \pm 1.04$ & $3.98 \pm 0.80$ & $4.45 \pm 0.89$ & $0.236(-)$ & $0.006(\uparrow)$ & $0.000(\uparrow)$ \\
\hline Potassium (mg) & $3450.8 \pm 895.6$ & $3840.2 \pm 736.9$ & $3858.1 \pm 693.3$ & $0.054(-)$ & $0.790(-)$ & $0.029(\uparrow)$ \\
\hline Calcium (mg) & $927.0 \pm 389.9$ & $989.4 \pm 333.0$ & $920.0 \pm 216.4$ & $0.785(-)$ & $0.949(-)$ & $0.835(-)$ \\
\hline Magnesium (mg) & $376.2 \pm 102.9$ & $405.5 \pm 81.8$ & $403.4 \pm 76.1$ & $0.049(\uparrow)$ & $0.907(-)$ & $0.064(-)$ \\
\hline Iron (mg) & $14.0 \pm 4.6$ & $14.1 \pm 2.9$ & $13.9 \pm 2.4$ & $0.867(-)$ & $0.780(-)$ & $0.911(-)$ \\
\hline Zinc (mg) & $13.4(8.2-25.1)$ & $13.5(9.3-23.7)$ & $13.4(8.1-20.6)$ & $0.737(-)$ & $0.460(-)$ & $0.794(-)$ \\
\hline Vitamin A equ. $(\mu \mathrm{g})$ & $1142.5 \pm 350.7$ & $1315.7 \pm 335.9$ & $1234.9 \pm 310.0$ & $0.360(-)$ & $0.932(-)$ & $0.406(-)$ \\
\hline Vitamin E equ. (mg) & $13.83 \pm 5.27$ & $13.29 \pm 3.45$ & $13.93 \pm 3.44$ & $0.579(-)$ & $0.515(-)$ & $0.923(-)$ \\
\hline Vitamin C (mg) & $120.1 \pm 46.3$ & $136.7 \pm 60.8$ & $133.4 \pm 41.6$ & $0.328(-)$ & $0.871(-)$ & $0.255(-)$ \\
\hline Folate (ug) & $374 \pm 124$ & $364 \pm 93$ & $364 \pm 73$ & $0.700(-)$ & $0.986(-)$ & $0.688(-)$ \\
\hline Vitamin $B_{1}(\mathrm{mg})$ & $1.49 \pm 0.51$ & $1.48 \pm 0.29$ & $1.50 \pm 0.29$ & $0.793(-)$ & $0.959(-)$ & $0.754(-)$ \\
\hline
\end{tabular}




\begin{tabular}{lllllll}
\hline Vitamin $\mathrm{B}_{2}(\mathrm{mg})$ & $2.01 \pm 0.63$ & $2.02 \pm 0.37$ & $2.00 \pm 0.33$ & $0.866(-)$ & $0.792(-)$ & $0.925(-)$ \\
Vitamin $\mathrm{B}_{6}(\mathrm{mg})$ & $2.21 \pm 0.76$ & $2.40 \pm 0.52$ & $2.36 \pm 0.53$ & $0.262(-)$ & $0.827(-)$ & $0.365(-)$ \\
Vitamin $\mathrm{B}_{12}(\mathrm{ug})$ & $6.7 \pm 5.6$ & $6.2 \pm 3.4$ & $5.3 \pm 3.2$ & $0.415(-)$ & $0.179(-)$ & $0.033(\downarrow)$ \\
Niacin equ. $(\mathrm{mg})$ & $20.6 \pm 9.5$ & $24.2 \pm 5.9$ & $23.3 \pm 6.6$ & $0.054(-)$ & $0.616(-)$ & $0.150(-)$ \\
\hline
\end{tabular}

${ }^{a}$ values are presented as mean \pm SD or as median and range; (DC), direction of change: (-) no significant changes, ( $\uparrow$ ) significant increase, $(\downarrow)$ significant decrease; $p$ value ${ }^{\mathrm{b}}$, D versus $\mathrm{B} ; p$ value ${ }^{\mathrm{c}}$, D\&J versus $\mathrm{D} ; p$ value ${ }^{\mathrm{d}}$, D\&J versus B; EA, energy availability; FFM\%, fat free mass percent; equ., - equivalent.

Table 3. The nutritional profile of freeze-dried beetroot juice

\begin{tabular}{|c|c|c|}
\hline Identified compound & Content per $100 \mathrm{~g}$ & Content per portion $(26 \mathrm{~g})$ \\
\hline Sucrose (g) & $62.60 \pm 7.75$ & 16.28 \\
\hline Fructose (g) & $1.95 \pm 0.00$ & 0.51 \\
\hline Malic acid (g) & $0.39 \pm 0.01$ & 0.10 \\
\hline Citric acid (g) & $14.50 \pm 2.29$ & 3.77 \\
\hline Vitamin C (mg) & $65.99 \pm 6.61$ & 17.16 \\
\hline Betanin-3-O-glucoside (mg) & $1430.10 \pm 193.08$ & 371.83 \\
\hline Betanidine (mg) & $29.31 \pm 0.90$ & 7.62 \\
\hline Total polyphenols (mg) & $147.46 \pm 15.41$ & 38.34 \\
\hline Total phenolic acids (mg) & $126.45 \pm 15.70$ & 32.88 \\
\hline Gallic acid (mg) & $69.77 \pm 7.44$ & 18.14 \\
\hline Chlorogenic acid (mg) & $51.31 \pm 8.95$ & 13.34 \\
\hline Ferulic acid (mg) & $5.37 \pm 0.82$ & 1.40 \\
\hline Total flavonoids (mg) & $21.01 \pm 0.92$ & 5.46 \\
\hline Quercetin-3-O-glucoside (mg) & $3.37 \pm 0.59$ & 0.88 \\
\hline Myrycetin (mg) & $2.40 \pm 0.71$ & 0.62 \\
\hline Quercetin (mg) & $7.31 \pm 0.32$ & 1.90 \\
\hline Luteolin (mg) & $5.34 \pm 0.59$ & 1.39 \\
\hline Kaempferol (mg) & $2.61 \pm 0.10$ & 0.68 \\
\hline
\end{tabular}

Values are presented as mean \pm SD.

In addition to changes in the absolute values of the studied parameters between the consecutive stages, many relationships between the examined variables were also observed. Values of $\mathrm{VO}_{2 \max }$ at all the stages $(\mathrm{B}, \mathrm{D}, \mathrm{D} \& \mathrm{~J})$ correlated with FFM\% $(\mathrm{r}=0.623, p=0.004 ; \mathrm{r}=0.505, p=0.028 ; \mathrm{r}=0.471, p=0.042$, respectively $)$. The analysis of such parameters as mean corpuscular hemoglobin (MCHC), RDW, PLT and MPV after D showed inverse correlations with their changes after D\&J J $(\mathrm{r}=-0.779, p=0.000 ; \mathrm{r}=-0.550, p=0.012 ; \mathrm{r}=-0.629, p=0.003 ; \mathrm{r}$ $=-0.705, p=0.001$, respectively). Additional activity of GPx before beetroot juice supplementation correlated negatively with changes of this enzyme after 4 weeks of consumption of the juice - GPx activity after D correlated with changes after D\&J $(r=-0.566, p=0.009)$.

\section{Discussion}

For the first time, our results have demonstrated a long-term effect of a diet and beetroot juice supplementation on hematological parameters, physical performance, and glutathione peroxidase activity in erythrocytes (Table 1). In the carried out study freeze-dried beetroot juice was administered, in which the level of major compounds and antioxidants was determined (Table 3). Taking into consideration the fact that nutritional value of a given food product is determined by many factors, including the region of cultivation, variety, fertilization, cultivation method, and technological process used (Kazimierczak et al., 2014; Lee et al., 2014), it seems that the analysis of the nutritional value of a given product in terms of the obtained therapeutic effects is a key element. For example, the 
administered by us beetroot juice was characterized by several times higher contents of total polyphenols, total phenolic acids, gallic acid, chlorogenic acid, quercetin, luteolin, and kaempferol but lower contents of betanin-3-O-glucoside, ferulic acid, total flavonoids, quercetin-3-O-glucoside, and myrycetin than the naturally fermented beetroot juice from organic and conventional production (Kazimierczak et al., 2014). In our study after beetroot juice supplementation, such beneficial effects as negative correlations of hematological parameters (MCHC, RDW, PLT, MPV) in D with their changes after D\&J $(p<0.000, p=0.012, p=0.003, p=0.001$ respectively) were observed, which indicates a normalizing effect of the therapy - the fencers with the lowest values of these parameters had the largest increase. Additionally at D\&J in comparison with B higher carbohydrate intake was also observed $(p<0.000)$. These positive effects on morphological parameters could have been a result of reduction of energy deficit and a higher activity of GPx and higher levels of bioactive chemicals: flavonoids, polyphenols, and betalains - with antioxidant properties, which beetroot was a good source of (Georgiev et al., 2010; Kugler et al., 2007; Kujala et al., 2002).

During a strenuous exercise, the metabolic rate in skeletal muscles can increase up to 100 times above that in the resting condition and in the mitochondria extremely increased oxygen utilization and elevated superoxide anion synthesis are observed (Jenkins, 1988). Therefore, in the case of high intensity as well as the long-time duration of exercise an increased oxidative modification of proteins, nucleic acids, and lipids occur (Fisher et al., 2011). Oxidative damage can also produce severe functional and structural perturbation of erythrocyte membranes by lipid peroxidation of their polyunsaturated fatty acid. Excessive lipid peroxidation of the cell membrane may be prevented or minimized by enzymatic mechanisms e.g. selenium-containing glutathione peroxidase (Mills, 1957) and nonenzymatic protective defense systems e.g. betalains, polyphenols, flavonoids (Affany, Salvayre, \& Douste-Blazy,1987; Tesoriere, Butera, Allegra, Fazzari, \& Livrea, 2005).

GPx by enzymatic detoxification of non-radical hydroperoxides regulates cellular oxidant status via the elimination of hydroperoxides and oxidation of low molecular weight thiols like reduced glutathione. This mechanism protects erythrocytes from oxidation (Rotruck et al., 1973). Beetroot is a very good source of potentially bioactive compounds such as phenolics ascorbic acid, carotenoids, and betalains (Ninfali \& Angelino, 2013). Another product, which is also rich in betalains is the fruit of cactus pear, a plant spread in warm areas and the Mediterranean region (Fernández-López \& Almela, 2001). In a study with healthy volunteers, the postabsorptive fate of dietary betalains has been investigated. That study's authors have shown that these compounds incorporate in the RBCs time-dependently (Tesoriere, Allegra, Butera \& Livrea, 2004). The same authors have also analyzed the resistance of $\mathrm{RBC}$ to oxidation through evaluation of the length of time required to start hemolysis. RBC were isolated at time intervals after feeding with cactus pear fruit and were submitted to oxidative injury by cumenehydroperoxide. The resistance to hemolysis of the cells isolated 3 and $5 \mathrm{~h}$ after the fruit meal was significantly higher in comparison to that of the homologous cells before fruit consumption. Also, ex vivo spiking of blood with betalains resulted in the incorporation of increasing amounts of these compounds in the RBCs and the betalain-enriched erythrocytes were more resistant to oxidative hemolysis than the nonenriched erythrocytes. A significant relationship has been also observed between the increase of resistance and the amount of the incorporated betalains (Tesoriere et al., 2005).

The beetroot juice supplemented in our study had a higher amount of flavonoid quercetin. In an experimental in vitro model with cumenehydroperoxide induced peroxidation of erythrocyte membrane and formation of malonaldehyde and fluorescent lipid-soluble products an antioxidant effect of various flavonoids has been analyzed. The highest protective effect, evaluated by inhibition of peroxidation product formation, has been displayed by quercetin and catechin (Affany et al., 1987). Also, another phenolic compound has the high antioxidant capacity - chlorogenic acid. It has been stated that this acid occurs mainly in the hydrophilic region of the erythrocyte membrane and modifies its properties. Such a location enables the chlorogenic acid to reduce free radicals around the cell and hinders their diffusion into the membrane interior of erythrocytes (Bonarska-Kujawa, Cyboran-Mikołajczyk, \& Kleszczyńska, 2015).

Favorable changes in red blood cell parameters observed after D\&J in comparison with D (Table 1) are the very important effects of a diet and beetroot juice supplementation. In terms of aerobic performance, it has been stated that mainly hemoglobin and hematocrit are key elements in increasing $\mathrm{VO}_{2 \max }$ and, for example, $\mathrm{VO}_{2 \max }$ is enhanced by approximately $1 \%$ for each $3 \mathrm{~g} / \mathrm{L}$ increase of hemoglobin (Otto, Montgomery \& Richards, 2013). Unfortunately after $\mathrm{D}$, in comparison with $\mathrm{B}$, significant adverse changes in $\mathrm{RBC}(p=0.045)$ were observed. This may be due to low energy, carbohydrates, and protein intake and a consequence of an imbalance in EA. During D\&J the fencers had higher EA in comparison with B (Table 2). Despite the fact that the athletes received individual dietary recommendations taking into account the number of consumed products and tailored to individual needs, they were not able to comply with these recommendations. So the low intake of energy and 
macronutrients is very often a problem in athletes. The International Olympic Committee defined this problem as Relative Energy Deficiency in Sport (RED-S). This syndrome refers to 'impaired physiological functioning caused by relative energy deficiency and includes, but is not limited to, impairments of metabolic rate, menstrual function, bone health, immunity, protein synthesis and cardiovascular health'. The main aetiological factor of these health problems is low energy availability (LEA), (Mountjoy et al., 2018). In a very wellcontrolled research conducted in women, it has been shown that optimal EA for a healthy physiological function is typically achieved at an EA of 45 $\mathrm{kcal} / \mathrm{kg}$ FFM/d (Loucks \& Heath, 1994; Loucks \& Thuma, 2003). Many body systems are substantially perturbed at an EA $<30 \mathrm{kcal} / \mathrm{kg} \mathrm{FFM} / \mathrm{d}$ and this value is historically a targeted threshold for LEA (Mountjoy et al., 2018). LEA leads among others to hematological dysfunction, including low ferritin and iron deficiency anemia in female athletes (Ackerman et al., 2018). The International Olympic Committee consensus declaration on relative energy deficiency in situations caused by unintentional under-eating recommends simple nutrition education. But if this intervention is insufficient, interdisciplinary support from a team of medical, diet, and mental health specialists should be considered to resolve this problem (Mountjoy et al., 2018). Perhaps such support guaranteed to our fencers would result in a better effect of realization of the dietary recommendations.

At the end of the study also RDW was significantly decreased $(p=0.006)$. In the general population as well as in patients with heart diseases higher RDW was associated with an increased risk of morbidity and mortality (Patel, Ferrucci, Ershler, Longo, \& Guralnik, 2009; Tonelli et al., 2008). In patients with chronic heart failure after 6 months of exercise training, a decrease in RDW was observed. The change in RDW after this training period was indirectly related to the change in $\mathrm{VO} 2$ peak and higher RDW was independently related to the impaired exercise capacity in this group of patients (Van Craenenbroeck et al., 2012). RDV was also decreased in professional canoe polo athletes after 3 weeks of paddling-based high-intensity interval training with a variable volume of training (Sheykhlouvand et al., 2018). To sum up, beneficial relationships between red cell parameters and their changes after 4 weeks of beet juice supplementation were observed (Table 1).

In our study fencers during consecutive stages gradually increased PA-GT $(p=0.018)$ and in parallel, for 8 weeks, they increased their energy intake $(p=0.001)$. Therefore, among others, in D\&J values of EA was only slightly lower than the recommended $30 \mathrm{kcal} / \mathrm{kg} \mathrm{FFM} / \mathrm{d}$. Also, protein intake was at the recommended level and no significant changes were observed at all the stages of the study (Table 2). Only intake of vitamin $\mathrm{B}_{12}$ at the end of the study was significantly lower than in at the baseline stage $(p=0.033)$, but the recommended dietary allowance (RDA) in Poland for men and woman above 18 years is $2.4 \mu / \mathrm{d}$ (Jarosz et al., 2017) and this means, that intake was about two times higher than the RDA value. In this study, despite no changes in body weight, there were beneficial changes in body composition - a slow decrease of FM\% and a slow increase of FFM\%. In this study after D\&J, the fencers before the aerobic performance test consumed a meal with beetroot juice and this caused a significant increase in $\mathrm{VO}_{2 \max }(p=0.001)$. This effect is well known and has been demonstrated in many studies (Bailey et al., 2009; Kelly et al., 2013; Lansley et al., 2011). Bearing in mind the well-known impact of red blood cells parameters on physical performance (Otto et al., 2013), a significant increase in RBC $(p=0.038)$ and HBG ( $p=$ 0.029 ) is the most important effect observed in this study after the stage with beetroot juice consumption (D\&J). The observed effect could have been a result of the action of bioactive compounds found in beetroot juice as well as a gradual increase in GPx activity and macronutrient intake which was connected with gradually increasing EA.

At the end of study, a significant improvement of MPV $(p=0.043)$ was also observed. An increased platelet volume is a well-known marker of platelet activation, wherein large platelets are reportedly more active than the small ones. For example, a significant association between MPV and running time has been demonstrated. The mechanism by which platelets may contribute to enhancing sports performance is pleiotropic and connected with releasing ergogenic mediators (Lippi et al., 2014), attenuation of neuropathic fatigue and pain (Kuffler, 2013) as well as triggering an increase in such important substances as NO into the circulation (Kasuya, Kishi, Sakita, Numano, \& Isobe, 2002). Our results also showed that WBC numbers were decreased after D $(p=0.020)$ and this condition disrupted the immune system, but after the consecutive stage with beetroot juice supplementation (D\&J) in this parameter, no significant changes were observed. Athletes, in comparison with the general population, more often suffer from health problems such as sore throats and flu-like symptoms. What is more, in athletes cold may last longer (Gleeson, 2007; Heath et al., 1991). The post-exercise immune response connected with a decreased WBC is similar to that seen in both infection and inflammation (Fisher-Wellman \& Bloomer, 2009).

The described results of the conducted study indicate that natural compounds present in beetroot juice may prevent and/or mitigate the effects of intensive training, which is connected with adverse changes in the red cells system. It is known that rupture and destruction of erythrocytes is a consequence of an intensive physical exercise. This effect is connected with a direct mechanical injury as well as with metabolic abnormalities such as hyperthermia, dehydration, hypotonic shock, hypoxia, lactic acidosis, shear stress, oxidative damage, proteolysis, or increased 
concentration of catecholamines and lysolecithin (Lippi \& Sanchis-Gomar, 2019). Thus, not only in athletes but also in other groups of people with metabolic abnormalities, which are mentioned above, beetroot juice may be a particular component of a diet.

Despite our efforts, our study has some limitations such as study time, number of the study subjects, no control group, or some problems with dietary intake. Some of these problems result from the specificity of the studied group of people. For the issue of study group size, I would like to emphasize that our research included the elite of fencers - the national team and that is a very small group of people. Extending this group to include people from the control group would make the study group heterogeneous, with varying levels of training. It is known that in people with a high level of training, physical performance improvement takes place much more slowly in comparison with people with a lower level of training. Besides, people with a higher level of training have different training regimens. Therefore, the obtained effect could be a result of differences in the training level and differences in the quantity and quality of their training. The period of observation during which the level and type of physical activity are at the same level constitutes is the second significant limitation. Throughout the whole year, the elite of fencers have a very diversified training program both for its quantity and quality. Our study was planned in the longest preparatory phase without planned changes in the quantity and quality of training. After this period, the fencers have a period of contests, during which the nature of training changes considerably. Additionally, periods with maximum burden associated with competing occur very frequently, which considerably changes the metabolism and influences the parameters studied by us. All these aspects meant that our observation time could not be longer. Among other things, in the studies in which beetroot juice was administered to the athletes, the observation periods were short. To the best of our knowledge, the longest period of supplementation with beetroot juice in athletes was 15 days (Vanhatalo et al., 2010). We were also unable to perfectly correct the energy intake. However, all these limitations indicate what problems occur in research involving such a specific group of people.

\section{Conclusions}

Our findings provide evidence that supports the hypothesis that long time (4 weeks) consumption of beetroot juice - a rich source of many bioactive compounds, may improve some hematological parameters, which are one of the key elements of physical performance. However, seems to be that this effect may be determined by an appropriate level of energy availability and dietary intake of other basic nutrients.

\section{Acknowledgments}

The results of the current study do not constitute an endorsement of the product by the authors or the journal. We thank WPPH "ELENA" Import - Export Franciszek Siegien for the preparation and delivery of beetroot juice. We thank all the participants of the study without whom the study would be impossible.

\section{Author Contributions}

Conceptualization, L. K., O. M. and W. W.; Methodology, L. K., and O. M.; Software, O. M.; Validation, J. G., E. H. and A. M.; Formal analysis, L. K., J. G., E. H.; Investigation, O. M.; Data curation, L.K. and O.M.; Writing — original draft preparation, L. K., O. M.; Supervision, O. M., J. G., E. H., and W.W.

\section{Funding}

Research financed by Polish Ministry of Science and Higher Education within funds of Faculty of Human Nutrition and Consumer Sciences, Warsaw University of Life Sciences (WULS), for scientific research.

\section{Competing Interests Statement}

The authors declare that there are no competing or potential conflicts of interest.

\section{References}

Ackerman, K. E., Holtzman, B., Cooper, K. M., Flynn, E. F., Bruinvels, G., Tenforde, A. S., \& Parziale, A. L. (2018). Low energy availability surrogates correlate with health and performance consequences of Relative Energy Deficiency in Sport. British Journal of Sports Medicine, 53(10), 628-633. http://dx.doi.org/10.1136/bjsports-2017-098958

Affany, A., Salvayre, R., \& Douste-Blazy, L. (1987). Comparison of the protective effect of various flavonoids against lipid peroxidation of erythrocyte membranes (induced by cumene hydroperoxide). Fundamental \& Clinical Pharmacology, 1(6), 451-457. https://doi.org/10.1111/j.1472-8206.1987.tb00578.x

Ainsworth, B. E., Haskell, W. L., Herrmann, S. D., Meckes, N., Bassett JR., D. R., Tudor-Locke, C., ... \& Leon, A. S. (2011). 2011 Compendium of Physical Activities: A Second Update of Codes and MET Values. Medicine 
\& Science in Sports \& Exercise, 43(8), 1575-1581. https://doi.org/10.1016/j.yspm.2011.08.057

Bailey, S. J., Winyard, P., Vanhatalo, A., Blackwell, J. R., Wilkerson, D. P., Tarr, J., ... \& Benjamin, N. (2009). Dietary nitrate supplementation reduces the $\mathrm{O} 2$ cost of low-intensity exercise and enhances tolerance to high-intensity exercise in humans. Journal of Applied Physiology, 107, 1144-1155. https://doi.org/10.1152/japplphysiol.00722.2009

Bonarska-Kujawa, D., Cyboran-Mikołajczyk, S., \& Kleszczyńska, H. (2015). Molecular mechanism of action of chlorogenic acid on erythrocyte and lipid membranes. Molecular Membrane Biology, 32(2), 46-54. https://doi.org/10.3109/09687688.2015.1031833

Bond, H., Morton, L., \& Braakhuis, A. J. (2012). Dietary Nitrate Supplementation Improves Rowing Performance in Well-Trained Rowers. International Journal of Sport Nutrition and Exercise Metabolism, 22(4), 251-256. https://doi.org/10.1123/ijsnem.22.4.251

Bondonno, C. P., Blekkenhorst, L. C., Liu, A. H., Bondonno, N. P., Ward, N. C., Croft, K. D., \& Hodgson, J. M. (2018). Vegetable-derived bioactive nitrate and cardiovascular health. Molecular Aspects of Medicine, 61, 83-91. https://doi.org/10.1016/j.mam.2017.08.001

Fernández-López, J. A., \& Almela, L. (2001). Application of high-performance liquid chromatography to the characterization of the betalain pigments in prickly pear fruits. Journal of Chromatography A, 913(1-2), 415-420. https://doi.org/10.1016/S0021-9673(00)01224-3

Fisher, G., Schwartz, D. D., Quindry, J., Barberio, M. D., Foster, E. B., Jones, K. W., \& Pascoe, D. D. (2011). Lymphocyte enzymatic antioxidant responses to oxidative stress following high-intensity interval exercise. Journal of Applied Physiology, 110(3), 730-737. https://doi.org/10.1152/japplphysiol.00575.2010

Fisher-Wellman, K., \& Bloomer, R. J. (2009). Acute exercise and oxidative stress: A 30 year history. Dynamic Medicine, 8(1), 1-25. https://doi.org/10.1186/1476-5918-8-1

Georgiev, V. G., Weber, J., Kneschke, E. M., Denev, P. N., Bley, T., \& Pavlov, A. I. (2010). Antioxidant activity and phenolic content of betalain extracts from intact plants and hairy root cultures of the red beetroot Beta vulgaris cv. Detroit dark red. Plant Foods for Human Nutrition, 65(2), 105-111. https://doi.org/10.1007/s11130-010-0156-6

Gleeson, M. (2007). Immune function in sport and exercise. Immune Function in Sport and Exercise, 103(2), 693-699. https://doi.org/10.1152/japplphysiol.00008.2007

Hallmann, E., Kazimierczak, R., Marszałek, K., Drela, N., Kiernozek, E., Toomik, P., ... \& Rembiałkowska, E. (2017). The nutritive value of organic and conventional white cabbage (Brassica oleracea 1. Var. Capitata) and anti-apoptotic activity in gastric adenocarcinoma cells of sauerkraut juice produced therof. Journal of Agricultural and Food Chemistry, 65(37), 8171-8183. https://doi.org/10.1021/acs.jafc.7b01078

Heath, G. W., Ford, E. S., Craven, T. E., Macera, C. A., Jackson, K. L., \& Pate, R. R. (1991). Exercise and the incidence of upper respiratory tract infections. Medicine and Science in Sports and Exercise, 23(2), 152-157. https://doi.org/10.1249/00005768-199102000-00002

Hu, M., Finni, T., Sedliak, M., Zhou, W., Alen, M., \& Cheng, S. (2008). Seasonal Variation of Red Blood Cell Variables in Physically Inactive Men: Effects of Strength Training. International Journal of Sports Medicine, 29(7), 564-568. https://doi.org/10.1055/s-2007-989320

Jarosz, M., Rychlik, E., Stoś, K., Wierzejska, R., Wojtasik, A., Charzewska, J., ... \& Chwojnowska, Z. (2017). Normy żywienia dla populacji Polski. Warsaw, Poland: Instytut Żywności i Żywienia

Jenkins, R. R. (1988). Free Radical Chemistry: Relationship to Exercise. Sports Medicine, 5(3), 156-170. https://doi.org/10.2165/00007256-198805030-00003

Kasuya, N., Kishi, Y., Sakita, S., Numano, F., \& Isobe, M. (2002). Acute vigorous exercise primes enhanced NO release in human platelets. Atherosclerosis, 161(1), 225-232. https://doi.org/10.1016/s0021-9150(01)00629-3

Kazimierczak, R., Hallmann, E., Lipowski, J., Drela, N., Kowalik, A., Püssa, T., ... \& Rembiałkowska, E. (2014). Beetroot (Beta vulgaris L.) and naturally fermented beetroot juices from organic and conventional production: metabolomics, antioxidant levels and anticancer activity. Journal of the Science of Food and Agriculture, 94(13), 2618-2629. https://doi.org/10.1002/jsfa.6722

Kelly, J., Vanhatalo, A., Wilkerson, D. P., Wylie, L. J., \& Jones, A. M. (2013). Effects of Nitrate on the Power-Duration Relationship for Severe-Intensity Exercise. Medicine \& Science in Sports \& Exercise, 45(9), 
1798-1806. https://doi.org/10.1249/mss.0b013e31828e885c

Kozlowska, L., Mizera, O., \& Mroz, A. (2020). An Untargeted Metabolomics Approach to Investigate the Metabolic Effect of Beetroot Juice Supplementation in Fencers-A Preliminary Study. Metabolites, 10(3), 100. https://doi.org/10.3390/metabo10030100

Kuffler, D. P. (2013). Platelet-Rich Plasma and the Elimination of Neuropathic Pain. Molecular Neurobiology, 48(2), 315-332. https://doi.org/10.1007/s12035-013-8494-7

Kugler, F., Graneis, S., Stintzing, F. C., \& Carle, R. (2007). Studies on Betaxanthin Profiles of Vegetables and Fruits from the Chenopodiaceae and Cactaceae. Zeitschrift Für Naturforschung C, 62(5-6), 311-318. https://doi.org/10.1515/znc-2007-5-601

Kujala, T., Vienola, M., Klika, K., Loponen, J., \& Pihlaja, K. (2002). Betalain and phenolic compositions of four beetroot ( Beta vulgaris ) cultivars. European Food Research and Technology, 214(6), 505-510. https://doi.org/10.1007/s00217-001-0478-6

Kyle, U. G., Bosaeus, I., De Lorenzo, A. D., Deurenberg, P., Elia, M., Gómez, J. M., ... \& Scharfetter, H. (2004). Bioelectrical impedance analysis-part I: review of principles and methods. Clinical Nutrition, 23(5), 1226-1243. https://doi.org/10.1016/j.clnu.2004.06.004

Lansley, K. E., Winyard, P. G., Fulford, J., Vanhatalo, A., Bailey, S. J., Blackwell, J. R., ... \& Jones, A. M. (2011). Dietary nitrate supplementation reduces the $\mathrm{O} 2$ cost of walking and running: a placebo-controlled study. Journal of Applied Physiology, 110(3), 591-600.https://doi.org/10.1152/japplphysiol.01070.2010

Lee, E. J., An, D., Nguyen, C. T. T., Patil, B. S., Kim, J., \& Yoo, K. S. (2014). Betalain and Betaine Composition of Greenhouse- or Field-Produced Beetroot (Beta vulgaris L.) and Inhibition of HepG2 Cell Proliferation. Journal of Agricultural and Food Chemistry, 62(6), 1324-1331. https://doi.org/10.1021/jf404648u

Lippi, G., Salvagno, G. L., Danese, E., Skafidas, S., Tarperi, C., Guidi, G. C., \& Schena, F. (2014). Mean Platelet Volume (MPV) Predicts Middle Distance Running Performance. PLoS ONE, 9(11), e112892. https://doi.org/10.1371/journal.pone.0112892

Lippi, G., \& Sanchis-Gomar, F. (2019). Epidemiological, biological and clinical update on exercise-induced hemolysis. Annals of Translational Medicine, 7(12), 270-270. https://doi.org/10.21037/atm.2019.05.41

Loucks, A. B., \& Heath, E. M. (1994). Induction of low-T3 syndrome in exercising women occurs at a threshold of energy availability. American Journal of Physiology-Regulatory, Integrative and Comparative Physiology, 266(3), R817-R823. https://doi.org/10.1152/ajpregu.1994.266.3.r817

Loucks, A. B., \& Thuma, J. R. (2003). Luteinizing Hormone Pulsatility Is Disrupted at a Threshold of Energy Availability in Regularly Menstruating Women. The Journal of Clinical Endocrinology \& Metabolism, 88(1), 297-311. https://doi.org/10.1210/jc.2002-020369

Lundberg, J. O., Weitzberg, E., \& Gladwin, M. T. (2008). The nitrate-nitrite-nitric oxide pathway in physiology and therapeutics. Nature Reviews Drug Discovery, 7(2), 156-167. https://doi.org/10.1038/nrd2466

Mills, G. C. (1957). Hemoglobin catabolism I. Glutathione peroxidase, an erythrocyte enzyme which protects hemoglobin from oxidative breakdown. Journal of Biological Chemistry, 229(1), 189-197.

Mountjoy, M., Sundgot-Borgen, J. K., Burke, L. M., Ackerman, K. E., Blauwet, C., Constantini, N... \& Budgett, R. (2018). IOC consensus statement on relative energy deficiency in sport (RED-S): 2018 update. British Journal of Sports Medicine, 52(11), 687-697. https://doi.org/10.1123/ijsnem.2018-0136

Ninfali, P., \& Angelino, D. (2013). Nutritional and functional potential of Beta vulgaris cicla and rubra. Fitoterapia, 89, 188-199. https://doi.org/10.1016/j.fitote.2013.06.004

Otto, J. M., Montgomery, H. E., \& Richards, T. (2013). Haemoglobin concentration and mass as determinants of exercise performance and of surgical outcome. Extreme Physiology \& Medicine, 2(1), 1-8. https://doi.org/10.1186/2046-7648-2-33

Paglia, D. E., \& Valentine, W. N. (1967). Studies on the quantitative and qualitative characterization of erythrocyte glutathione peroxidase. The Journal of Laboratory and Clinical Medicine, 70(1), 158-169.

Patel, K. V., Ferrucci, L., Ershler, W. B., Longo, D. L., \& Guralnik, J. M. (2009). Red Blood Cell Distribution Width and the Risk of Death in Middle-aged and Older Adults. Archives of Internal Medicine, 169(5), 515-523. https://doi.org/10.1001/archinternmed.2009.11

Potgieter, S. (2013). Sport nutrition: A review of the latest guidelines for exercise and sport nutrition from the 
American College of Sport Nutrition, the International Olympic Committee and the International Society for Sports Nutrition. South African Journal of Clinical Nutrition, 26(1), 6-16. https://doi.org/10.1080/16070658.2013.11734434

Rotruck, J. T., Pope, A. L., Ganther, H. E., Swanson, A. B., Hafeman, D. G., \& Hoekstra, W. G. (1973). Selenium: Biochemical Role as a Component of Glutathione Peroxidase. Science, 179(4073), 588-590. https://doi.org/10.1126/science.179.4073.588

Shepherd, A. I., Gilchrist, M., Winyard, P. G., Jones, A. M., Hallmann, E., Kazimierczak, R., ... \& Wilkerson, D. P. (2015). Effects of dietary nitrate supplementation on the oxygen cost of exercise and walking performance in individuals with type 2 diabetes: a randomized, double-blind, placebo-controlled crossover trial. Free Radical Biology and Medicine, 86, 200-208. https://doi.org/10.1016/j.freeradbiomed.2015.05.014

Sheykhlouvand, M., Gharaat, M., Khalili, E., Agha-Alinejad, H., Rahmaninia, F., \& Arazi, H. (2018). Low-volume high-intensity interval versus continuous endurance training: Effects on hematological and cardiorespiratory system adaptations in professional canoe polo athletes. The Journal of Strength \& Conditioning Research, 32(7), 1852-1860. https://doi.org/10.1016/j.scispo.2016.02.007

Tesoriere, L., Allegra, M., Butera, D., \& Livrea, M. A. (2004). Absorption, excretion, and distribution of dietary antioxidant betalains in LDLs: Potential health effects of betalains in humans. The American Journal of Clinical Nutrition, 80(4), 941-945. https://doi.org/10.1093/ajcn/80.4.941

Tesoriere, L., Butera, D., Allegra, M., Fazzari, M., \& Livrea, M. A. (2005). Distribution of betalain pigments in red blood cells after consumption of cactus pear fruits and increased resistance of the cells to ex vivo induced oxidative hemolysis in humans. Journal of Agricultural and Food Chemistry, 53(4), 1266-1270. https://doi.org/10.1021/jf048134+

Tonelli, M., Sacks, F., Arnold, M., Moye, L., Davis, B., \& Pfeffer, M. (2008). Relation Between Red Blood Cell Distribution Width and Cardiovascular Event Rate in People With Coronary Disease. Circulation, 117(2), 163-168. https://doi.org/10.1161/circulationaha.107.727545

Van Craenenbroeck, E. M., Pelle, A. J., Beckers, P. J., Possemiers, N. M., Ramakers, C., Vrints, C. J., ... \& Conraads, V. M. (2012). Red cell distribution width as a marker of impaired exercise tolerance in patients with chronic heart failure. European Journal of Heart Failure, 14(1), 54-60. https://doi.org/10.1093/eurjhf/hfr136

Vanhatalo, A., Bailey, S. J., Blackwell, J. R., DiMenna, F. J., Pavey, T. G., Wilkerson, D. P., ... \& Jones, A. M. (2010). Acute and chronic effects of dietary nitrate supplementation on blood pressure and the physiological responses to moderate-intensity and incremental exercise. American Journal of Physiology-Regulatory, Integrative and Comparative Physiology, 299(4), R1121-R1131. https://doi.org/10.1152/ajpregu.00206.2010

\section{Copyrights}

Copyright for this article is retained by the author(s), with first publication rights granted to the journal.

This is an open-access article distributed under the terms and conditions of the Creative Commons Attribution license (http://creativecommons.org/licenses/by/4.0/). 